\title{
Resource Sharing within an International Library Network: using technology and professional cooperation to bridge the waters
}

\author{
Barbara A. Butler, Janet Webster, \\ Steven G. Watkins and James \\ W. Markham
}
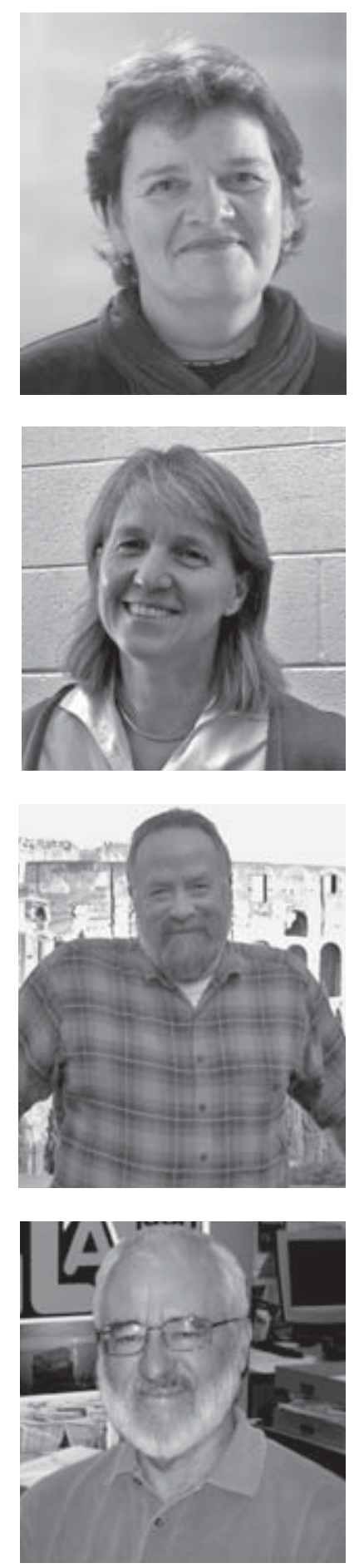

About the authors: page 198

\begin{abstract}
The International Association of Aquatic and Marine Science Libraries and Information Centers (IAMSLIC), comprised of 325 members from 86 countries, has a long history of resource sharing based on personal connections among its members. In 2002, IAMSLIC developed a resourcesharing system using a unified search interface that relies on Z39.50 broadcast search capabilities to query individual catalogs. In addition to the IAMSLIC Z39.50 Distributed Library, which searches standard OPAC catalogs, smaller libraries can share library holdings through the online Union List of Marine and Aquatic Serials. Member libraries may submit interlibrary loan requests for items located through either avenue. This successful program may serve as a model for other library organizations interested in sharing resources and extending access to subject-specific materials amongst member libraries.
\end{abstract}

Keywords: aquatic libraries; IAMSLIC; interlibrary loan; marine libraries; resource sharing

\section{Introduction}

Resource sharing, a well-established practice among libraries in most developed countries, cannot be taken for granted in all libraries. Barriers to sharing include underdeveloped infrastructures, institutional restrictions on cooperation and lack of staff expertise. Even those with the luxury of excellent interlibrary loan (ILL) systems occasionally use a personal connection or manipulate the established system to get an item quickly or track down the obscure item. Professional networks and personal contacts can be useful for rush requests or finding specialized, uncataloged resources but this process takes time and even the best personal network can fail. Members of an organization may rely on an e-mail discussion list to alert colleagues of their needs. However, discussion lists can be flooded with interlibrary loan requests to the detriment of professional discussion. Established interlibrary loan processes are appropriate for the bulk of resource-sharing requests for those with access to such processes; yet there remains a need for efficient use of professional networks to supplement traditional ILL services and, in the case of colleagues in the developing world, to establish resource-sharing options. A professional organization builds the capacity, or self-sufficiency, of all members by endorsing a resourcesharing system for its network. Improving the skills of members, and validating the essential importance of library services to their institutions, are two examples of this. The International Association of Aquatic and Marine Science Libraries and Information Centers (IAMSLIC) developed a resource-sharing system that uses our professional network to enhance the library services our members provide. 


\section{Resource Sharing in IAMSLIC: A Specialized Library Association}

Members of IAMSLIC work in libraries ranging from large marine and oceanographic institutes to small field station libraries. Their mandates vary, and this is reflected in the size and focus of their collections. Members acknowledge that one of the association's strengths is our ability to communicate and share resources within a somewhat cohesive community. IAMSLIC members are committed to sharing resources and respond to the needs of professional colleagues sometimes in spite of institutional policies, such as cost recovery and priority users. While committed in spirit, members face challenges with the practicalities of sharing resources given the spectrum of policies, library sizes and locations.

Major libraries can be overwhelmed with requests as they are seen as having the needed resources; but among IAMSLIC libraries, many of the smallest collections have both core resources and highly desirable unique items. The biggest challenges in accessing smaller library catalogs are searching and requesting items across a wide variety of systems. Our library systems range from sophisticated commercial products to homegrown spreadsheets. Staffing also runs the gamut from the large university library to the marine laboratory library with a staff of one. Finally, IAMSLIC is international: 325 members are spread among 86 countries throughout the world; we speak different languages; we have varying degrees of Internet access; and we operate in diverse information landscapes. Shared cataloging utilities and interlibrary loan systems are not a given in IAMSLIC member libraries and neither are MARC records. Our goal is for all interested members to participate in the resourcesharing program. Those from small libraries with core or specialized collections can make those materials more widely available and requests for more obscure items can be directed to larger research collections. Identifying and sharing our collections enhances access for all and remains a priority for our organization.

Since IAMSLIC's inception in 1975, we have relied on several tools to allow us to share subject specific resources needed by our patrons (See Table 1). The older tools were problematic yet useful. Serials lists and directories need constant updating to remain current and comprehensive. Without paid staff, it was difficult to ensure that listings were consistent and reflected developing technologies. For instance, our early directory focused on the marine components of our collections, yet was not expanded to include aquatic (freshwater) collections when our organization expanded in scope to include that perspective. Also, changes in document delivery technology such as ARIEL and new modes of communication such as e-mail were not captured and tracked in our International Directory of Marine Science

\begin{tabular}{|l|l|l|l|}
\hline Date & \multicolumn{1}{|c|}{ Title } & \multicolumn{1}{c|}{ Format } & \multicolumn{1}{c|}{ Content } \\
\hline 1984 & $\begin{array}{l}\text { MUSSEL: A Union List of } \\
\text { serials in marine science } \\
\text { libraries }\end{array}$ & Microfiche & $\begin{array}{l}\text { 10,000 marine science } \\
\text { periodicals from } \\
5 \text { 5 libraries (Meadows } \\
\text { et al., 1984) }\end{array}$ \\
\hline 1987 & $\begin{array}{l}\text { International Directory } \\
\text { of Marine Science Libraries } \\
\text { and Information Centers }\end{array}$ & Ring binder & $\begin{array}{l}\text { Contact information } \\
\text { and lending policies for } \\
\text { IAMSLIC member } \\
\text { libraries (Winn, 1987) }\end{array}$ \\
\hline 1990 -present & $\begin{array}{l}\text { Union List of Marine and } \\
\text { Aquatic Serials }\end{array}$ & $\begin{array}{l}\text { Telnet access } \\
1990-96 ; \text { Web access } \\
1997-99 ; \text { MySQL } \\
\text { relational database } \\
\text { 2000-present }\end{array}$ & $\begin{array}{l}\text { Journal holding records } \\
\text { from a number of } \\
\text { IAMSLIC libraries } \\
\text { (Watkins and } \\
\text { Wible, 1992) }\end{array}$ \\
\hline 1991-present & IAMSLIC Discussion List & E-mail & $\begin{array}{l}\text { Discussion list open to } \\
\text { IAMSLIC members } \\
\text { and non-members }\end{array}$ \\
\hline
\end{tabular}

Table 1. IAMSLIC resource sharing efforts. 
Libraries and Information Centers. The Union List of Marine and Aquatic Serials (Union List) has evolved along with changes in technology. Initially, it was compiled from DOS files with simple record delimiters. Now, its web front end and online forms enable all libraries to easily add, edit and manage their own records. The IAMSLIC e-mail discussion list, as with other subject specific library lists, became a major resource-sharing tool as members (and non-members) posted requests to the group. It is a fast and easy way to communicate, but also inefficient in that more than 300 people received the same request.

\section{The Problem with Resource Sharing}

We had a good electronic serials holdings resource and a means to communicate through the discussion list, yet were not satisfied with the inefficiency and inequity of our approach to resource sharing. An analysis of IAMSLIC discussion list postings in 1996 revealed that while the total postings to the list remained the same, the percentage due to ILL requests increased dramatically (Butler, 1997). The trend continued as ILL requests accounted for 45 percent of the discussion list postings the following year, higher than many other subject specific library discussion lists (Markham, 1998). A comparison of ten scitech library e-mail discussion lists showed that IAMSLIC had a higher percentage of total messages concerning ILL than any other list (Duda, Meszaros and Markham, 1997). IAMSLIC created a Resource Sharing Committee charged with investigating why our current tools were not working and recommending new approaches to the issue. The committee examined many different possibilities: the use of IAMSLIC regional groups as the 'first stop' for resource sharing; a three-tier system that guaranteed larger libraries last resort status; a separate listserv for ILL; partnering between large and small libraries; and a voucher system. None of these options worked well for IAMSLIC.

IAMSLIC took the first step towards formalizing the resource-sharing program and, as a compromise, continued to accept resource-sharing requests on the e-mail discussion list with the stipulation that the subject line must say 'ILL' and include the title being sought to allow easy filtering by those unable or unwilling to supply interlibrary loans. The discussion list remained the primary ILL vehicle, and there were no significant improvements in our resource-sharing system. We lacked an ILL generating system; requesters did not always follow established guidelines; the e-mail discussion list remained open to non-members; and the responsibility for searching resided with the lender.

Looking beyond our network, we found a paucity of models that addressed the use of the professional network for resource sharing. There has been a concerted effort towards developing better end-user access to interlibrary loan and document delivery (Morris and Jacobs, 1999; Leon et al., 2003). Cornish discusses the move away from centralized interlibrary loan, espouses the potential of small, specialized collections, and suggests that alternative models to countrycentric systems are possible (1991). The growth of consortial borrowing enhances access for the members of those networks, yet poses challenges (Brack et al., 1998; Weech, 2002; Bailey-Hainer, 2004). The UNIverse Project attempted to build a union catalog across countries with the eventual aim of providing unmediated access for library users throughout the European Union (Birch and Pettman, 2000). The pilot, using Z39.50, was successful, but funds for its implementation were not forthcoming. This is one example of resourcesharing projects that are reliant on significant funding, as well as consistent participation by all within the network, both of which pose difficulties for small, under-funded or specialized libraries and their professional networks (Clissman et al., 1998; Van Borm, 2004; Weech, 2002). However, many of the limitations UNIverse's creators discovered mirror the challenges IAMSLIC faced in developing a system (Birch and Pettman, 2000):

- the inconvenience of moving between physically disparate catalogs

- the problems of different record formats and languages as well as duplicate records

- the issue of scalability

- the disjuncture between searching and requesting

For IAMSLIC, we were looking for a system that would ultimately better serve our individual libraries' users, but would do so by better serving our members as librarians. Our focus has been to train and collaborate with each other rather than simply to supply articles to individual researchers, which was the historical pattern. By increasing IAMSLIC members' ability to find needed 
material, their suite of resources for serving their end users would expand and effectively raise the profile of librarians and libraries within their parent institutions. Our resource-sharing system emphasizes that all members have a responsibility to learn new skills and commit to the two-way transfer of information. This is particularly important to members in institutions with no cultural or technical history of resource and information sharing among libraries. IAMSLIC, a small organization with minimal dues, had to rely on volunteers to both create the system and maintain it. We needed a decentralized system that used international standards and was accessible by all members willing to participate. We wanted to exploit the growing ubiquity of the Internet to share unique collections equitably.

\section{Developing the Solution}

Creating our resource-sharing system was an evolutionary process. In 2000, the United States National Oceanic and Atmospheric Administration (NOAA) Coastal Services Center developed a website to facilitate access to coastal resources through a federated search of library catalogs (Ball, 2001). NOAA offered to include IAMSLIC and the IAMSLIC Linking Libraries Project was established as a way to share online catalogs. In the system, a single query could theoretically search all Z39.50-compliant IAMSLIC catalogs. The variety of catalogs proved to be a technical challenge as not all member libraries have OPACs or Z39.50 capability. Even so, this was an important step towards better sharing through improved searching capability. We still lacked a way to complete the ILL transaction from within the system. We also wanted to involve all members in sharing, so needed ways to include those without Z39.50-compatible catalogs.

In 2002, the IAMSLIC Z39.50 Distributed Library (Distributed Library) was launched building on the NOAA model (Watkins, 2003). Initially, 44 libraries out of roughly 250 IAMSLIC members participated in the project. Implementing Z39.50 search capabilities to the Union List database so that it could be searched simultaneously with the library catalogs allowed additional libraries to participate in the program as lenders. Members can add serial holdings to this database instead of, or in addition to, linking their catalog. As most resource-sharing requests in the sciences are for journal articles, enriching this resource is essential to a successful system. The technical 'fix' for enabling Z39.50 searching of the Union List appears in Figure 1.

A standard Perl query script extracts holding records from the database. Output is formatted using basic XML markup tags corresponding to MARC fields and subfield delimiters. An XMLto-MARC 'crosswalk' (the MARC:XML module available from the CPAN Perl archive) converts records from XML format into USMARC format. MARC records are indexed using open-source Zebra Z39.50 server software from IndexData in Denmark and made searchable via the Z39.50 broadcast search interface.

A sample record tagged in the XML format appears below:

$<$ record $>$

$<$ field type="000">02652cas 2200229 a 4500</field $>$

$<$ field type="001" $>$ ulist17</field $>$

$<$ field type="003" $>$ UnionList $</$ field $>$

$<$ field type="005">20050115153755.7</field >

$<$ field type="245" i1=" " i2=" ">

$<$ subfield type="a" $>$ Anales del Instituto de Investigaciones Marinas de Punta de

Betin $</$ subfield $>$

$</$ field $>$

$<$ field type="500" i1=" "i2=" ">

$<$ subfield type="a"> IFM-GEOMAR Library Westufer Leibniz-Institut fur

Meereswissenschaften has: 9.1972 - 24.1995 / Suppl. 1.1977</subfield $>$

$</$ field $>$

$</$ record $>$

Figure 1. Crosswalking XML to MARC to enable Z39.50 access. 
All IAMSLIC members with Z39.50-capable catalogs were encouraged to allow their catalogs to be searched via this system. Consistent retrieval from the wide range of Z39.50 servers was challenging, so we refined our search system. A new broadcast search interface was developed using the PHP/YAZ open-source software from IndexData of Denmark (Watkins, 2003). The PHP/YAZ interface was customized to offer added functionality, such as displaying active links to electronic full-text documents using the MARC 856 field. As a further refinement, ISSN links to the native OPAC interfaces at participating libraries were added to facilitate access to more detailed holdings and circulation status information. Once we were able to consistently search catalogs from individual libraries as well as the Union List, we were ready to develop an easy-to-use ILL requesting module.

We devised a means to search and automatically generate a request, sending the borrowing library's information to the targeted lender. For participating libraries whose catalogs support Z39.50 queries, updating holdings is no longer of concern because the search is performed against their live library catalogs. The distributed library is open to anyone to search (http://library.csumb. edu/iamslic/ill/search.php). The resource-sharing component, limited to IAMSLIC members, works as follows:

- IAMSLIC members begin by searching either the Distributed Library, which includes all Z39.50-compliant IAMSLIC catalogs and the Union List, or they may search or browse the Union List independently.

- Search results are returned with Union List results appearing at the top of the list in order to distribute the lending workload to all IAMSLIC libraries, including small institutions and libraries from developing nations.

- The borrowing member chooses a catalog record from a lending library; provides a password; and is presented with the profile of the lending library (Figure 2).

- The borrower then selects his or her library profile from the database and is authenticated through an automatic check of the IAMSLIC membership directory. Their library borrower profile only appears in the system if their membership is current (Figure 3). The borrower then generates the ILL transaction, which is e-mailed to the lending library and copied to the requestor.

- The transaction is finalized between the borrower and the lender. The book is shipped or the article is delivered. Most IAMSLIC libraries

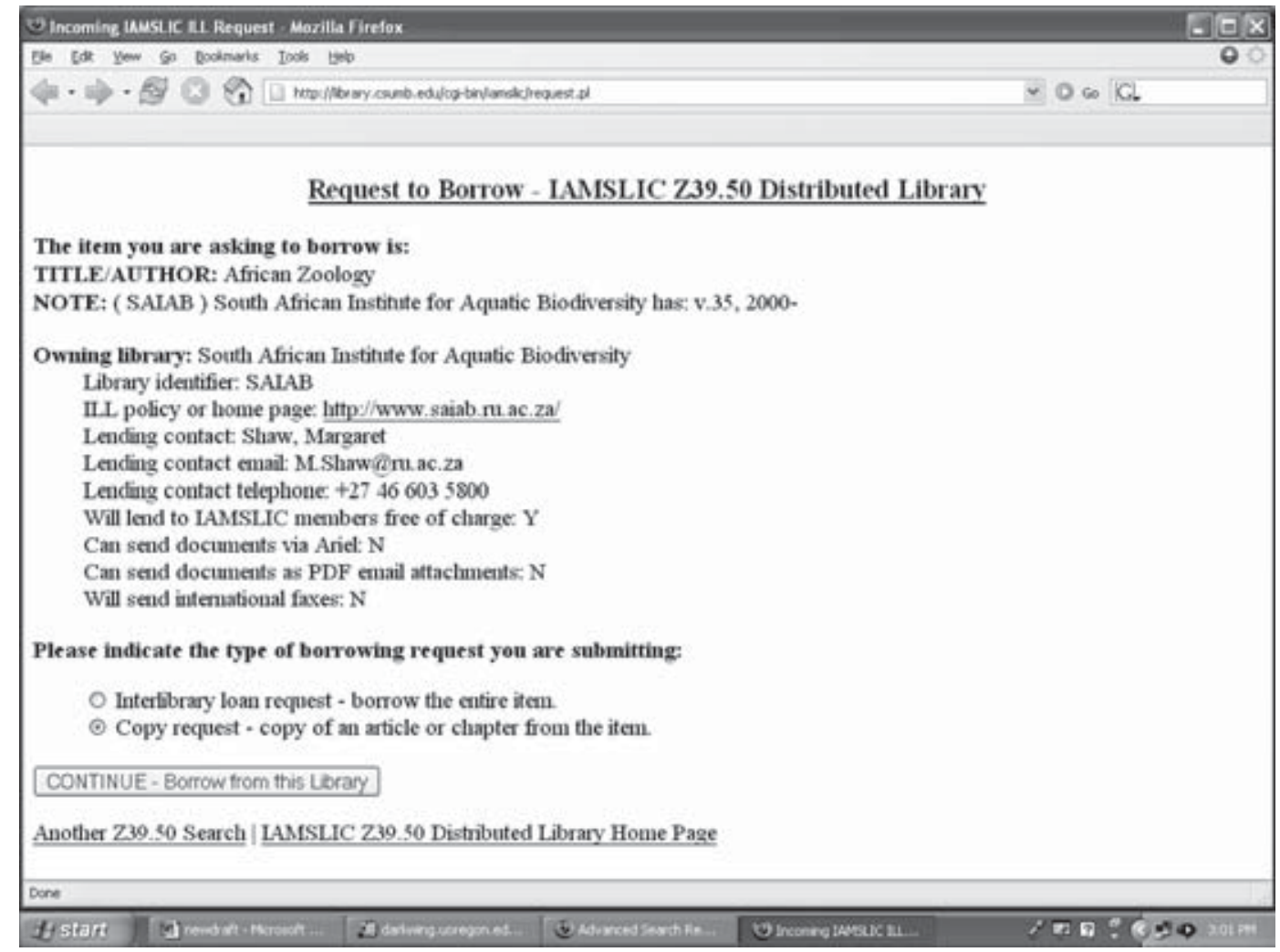

Figure 2. The lending library profile. 


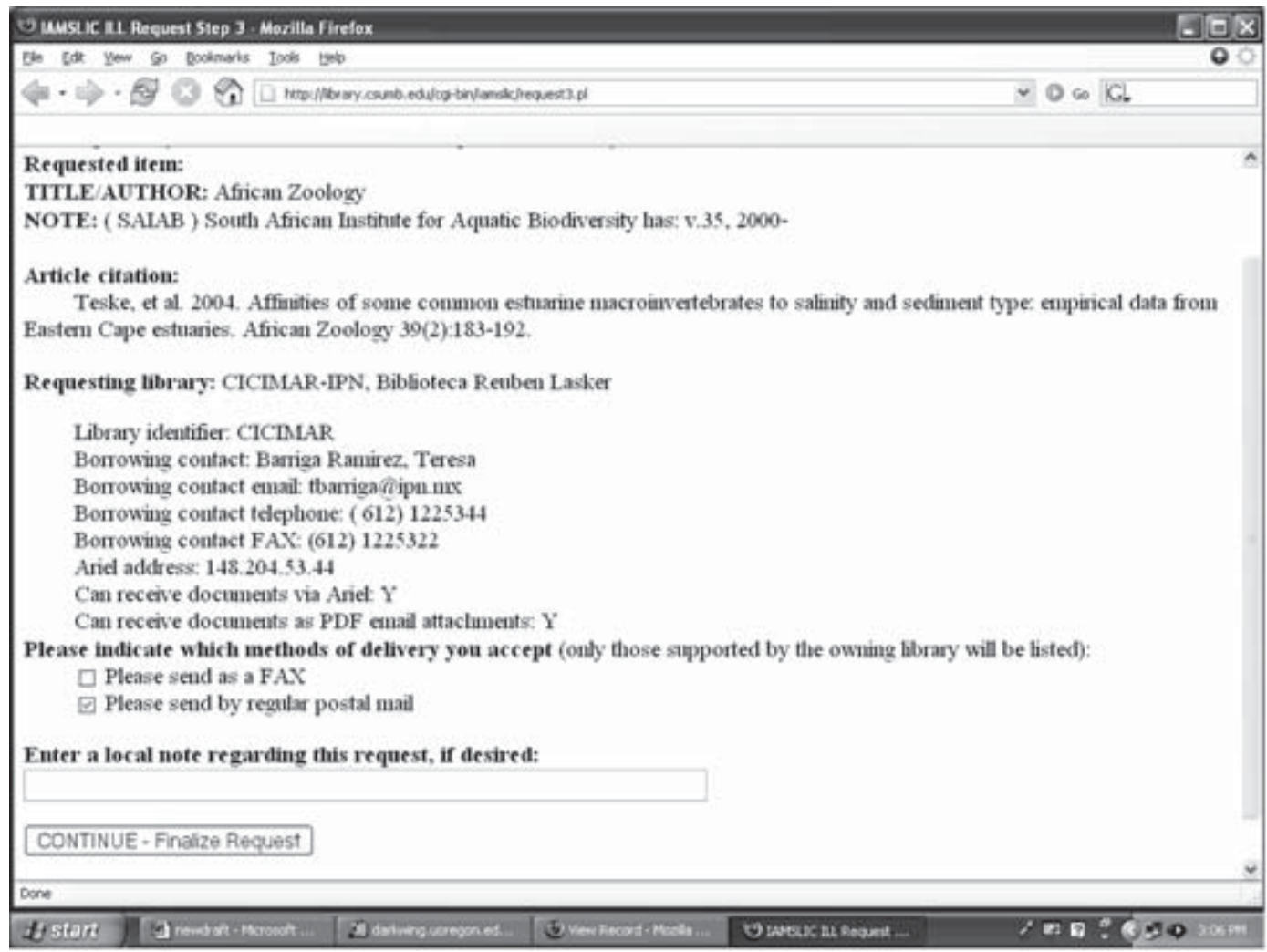

Figure 3. The borrowing library profile and request generator.

supply articles via ARIEL, with many members receiving articles as e-mail attachments. The available delivery options are clearly explained in the borrowing and lending profiles.

\section{Assessing Success}

Throughout the process of developing and refining our resource-sharing tools, IAMSLIC has had seven goals, all geared towards an equitable, inclusive and efficient system. Each goal provides a measure of success.

\section{Goal 1: Distribute the Interlibrary Loan Burden}

At issue is the common problem of the largest collections being perceived as being the best resource or the best equipped to handle requests. Unfortunately, this perception is often wrong as these institutions suffer limitations on staffing and capacity along with the rest of us. The Distributed Library displays records from the Union List at the top of the results screen, therefore the holdings of smaller libraries appear first. Larger institutions such as the Marine Biological Laboratory (Massachusetts, USA) or Scripps Institution of
Oceanography (California, USA) are given 'last resort' status and appear at the bottom of the listings with the note 'Please request from another library if available elsewhere.' Each transaction is recorded so that requesting patterns can be studied.

There are now 84 supplying libraries sharing the workload. Fifty-four lenders have included their holdings in the Union List, 39 lenders make their catalogs available via Z39.50, and ten libraries offer both. During the first four years in operation (July 2002-June 2006), the Distributed Library processed 2,032, 2,966, 2,733 and 2,741 requests respectively. Figure 4 illustrates that the 2005/2006 workload was distributed across 68 lenders. On average, no library received more than one request per day. The workload has been distributed broadly and our last resort lenders have been protected from filling requests from commonly held titles.

\section{Goal 2: Increased Efficiency}

ILL requests go directly to individual lenders, rather than the approximately 300 subscribers to the IAMSLIC e-mail discussion list. Figure 5 shows a summary of the percentage of ILL requests compared to total postings on the 


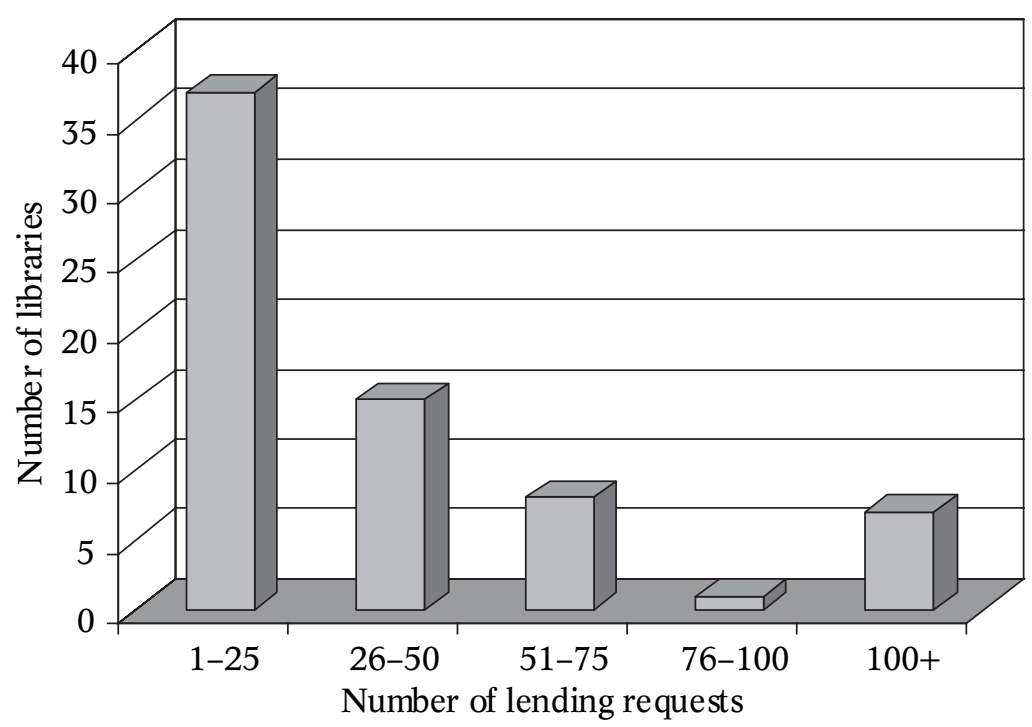

Figure 4. Distribution of lending workload, July 2005-June 2006.

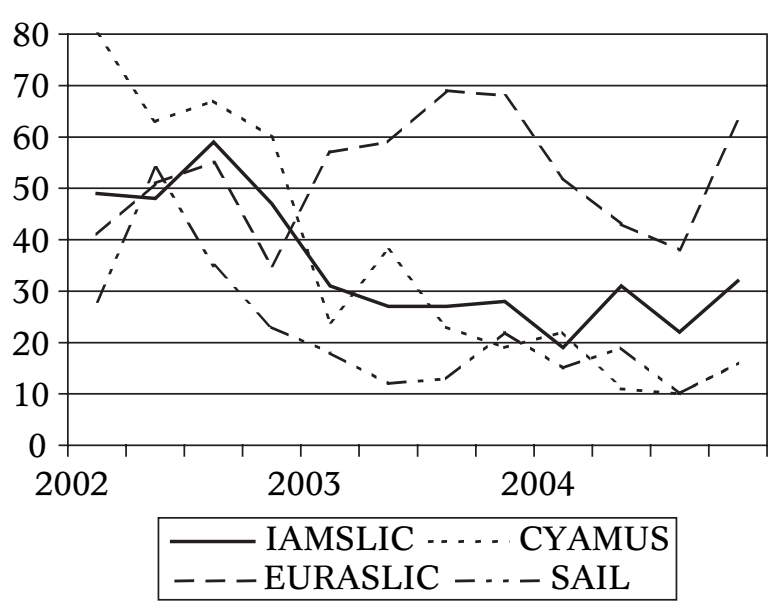

Figure 5. Percentage of IAMSLIC and regional group listserv postings due to ILL requests (after Markham, 2004).

various discussion lists related to IAMSLIC. The percentage of postings on the IAMSLIC discussion list decreased from 51 to 29 percent during the first year of the Distributed Library. This pattern holds true for the discussion lists of two IAMSLIC Regional Groups (Cyamus and SAIL). The EURASLIC Regional Group did not see the same decline because this group has a large number of non-IAMSLIC members who do not have access to the IAMSLIC ILL module and still post ILL requests to their regional discussion list.

\section{Goal 3: Include All Compatible Catalogs in the Distributed Library}

There are currently 39 participating libraries whose catalogs are searchable via Z39.50 and new additions occur on a regular basis. Some libraries have been unable to participate because their holdings are part of larger institution-wide catalogs. In other instances, we have encountered technical problems when attempting to connect to catalogs over the Z39.50 protocol. However, when combined with the Union List participants, nearly 25 percent of the IAMSLIC membership is represented, with a solid geographic and institutional mix. Requests have been generated from more than 100 different libraries in 39 countries (Figure 6), and 68 libraries from 18 different countries have filled requests. In the first two years of the program, US libraries received nearly 90 percent of all requests. However, during the past year, the geographic distribution of lending activity has shifted markedly, with 56 percent of requests supplied by US libraries and the remainder supplied from libraries as shown in Figure 7. Presentations at our annual conference and regional meetings familiarize members with the value of joining the Distributed Library. Growth appears to be steady as word spreads.

\section{Goal 4: Include Small Library Holdings in the Union List of Marine and Aquatic Serials}

The web-based Union List is available to any IAMSLIC member, as is help with loading and updating records (http://library.csumb.edu/ iamslic/unionlist/index.php). The interface is easy to maneuver and works even with slow Internet connections. As an indicator of its utility, 54 member libraries use the online Union List to access and update their serials holdings. Recently, we initiated the Listado Unido de Publicaciones 


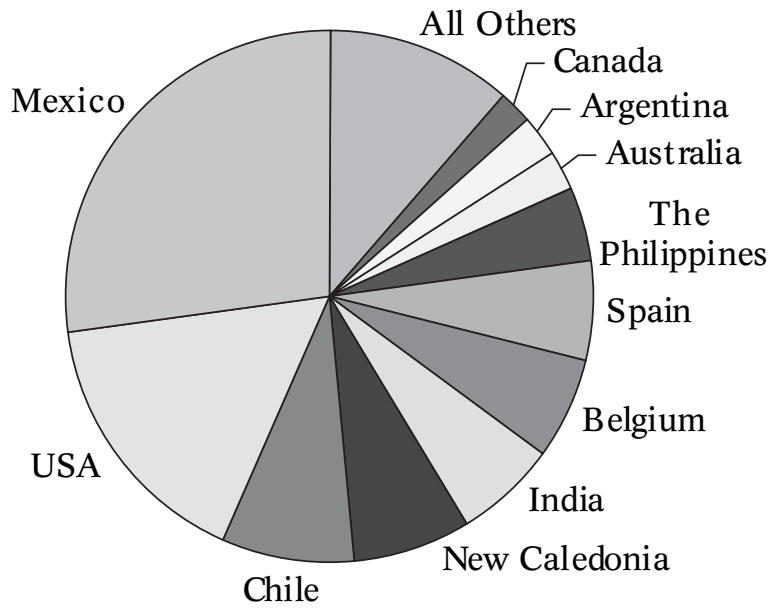

Figure 6. Borrowing by country, July 2005-June 2006.

Periodicas (Latin American Union List of Marine and Aquatic Serials) at the request of the members in that region. It includes holdings from eighteen libraries, ranging from the Cuba National Aquarium Library to the larger collection of the CICESE in Ensenada, Mexico. Six of these eighteen libraries had their holdings represented in the original Union List and, as expected, by increasing the number of libraries represented in their regional Union List, the percentage of requests filled by Latin American libraries quadrupled, from 3.8 percent of all requests to 15.7 percent in the first year after the regional Union List was established. A similar effort is underway with member libraries in Africa. The regional lists are a mechanism to get more libraries involved in the Distributed Library as well as enhancing resource sharing within the regions.

\section{Goal 5: Train Members to use the ILL Module}

The IAMSLIC Resource Sharing Committee developed a PowerPoint presentation, in English, Spanish and French, to train users in both the Distributed Library and the ILL module (http://www.iamslic.org/index.php?section=27). Information is sent to every new IAMSLIC member and training sessions are included at the annual conference. When requests appear on the IAMSLIC Discussion List, we post a message describing how to use the library and encouraging people to try that avenue before resorting to the discussion list.

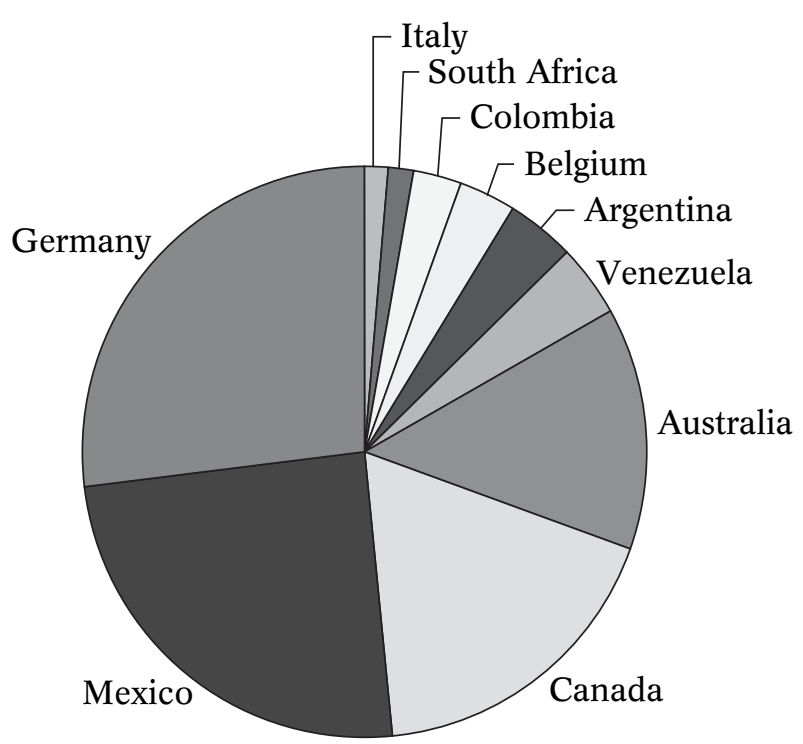

Figure 7. Lending by country, July 2005-June 2006 (56.2\% of all requests were received by US libraries).

\section{Goal 6: Help Users Overcome Common Mistakes}

When members are not able to find an item they need in the Distributed Library or the Union List, their requests usually appear on the IAMSLIC Discussion List. The Resource Sharing Committee uses these as teachable moments to disseminate advice on effective strategies for using the system and to build members' knowledge.

\section{Goal 7: Make the System Sustainable}

The system needs to be manageable by volunteers and run on a participating institution's server. Initial system development benefited from a dedicated member's willingness to commit sabbatical time to develop the ILL module and to adapt and enhance the open-source software to meet IAMSLIC's specific needs. Ongoing maintenance requires a minimal time commitment to add new lenders, develop new features and to periodically update the underlying software. The individual lenders cover the cost of sharing materials. Responsibility for copyright issues resides with the borrowers. Training of new members and maintenance of the online IAMSLIC membership directory are handled by standing committees.

\section{Comparing Fill Rates}

We are accomplishing our goals of capacity building and development of a robust, equitable 
system. However, the bottom line in any resourcesharing system is the fill rate: do members get their requests filled? We automatically track the number of requests made, but not the number of requests filled. However, a small sampling of the top lenders indicates higher fill rates for IAMSLIC requests than for requests generated through OCLC, which is the prevalent ILL system at these institutions (Table 2). This suggests that the Distributed Library is an efficient tool and that our collections form a cohesive and rich resource for our members.

In two cases where IAMSLIC fill rates were lower (Oregon Institute of Marine Biology and Duke Marine Laboratory), requests made for items located in main campus collections were not filled. Both libraries now share their holdings via the Union List rather than through their OPACs and expect to show higher fill rates in the future. Fill rates from the Marine Biological Laboratory, a last resort lender, may be lower because many requests received by them are not as easily filled, or they encourage requestors to look elsewhere for items that are readily available.

\section{Sharing Resources Successfully}

Resource sharing is a natural component of a library's services. It is not always the focus of a library association, but it can be. Multiplying the power of the professional network reaps benefits for all. We remain committed to developing our resource-sharing system, as it is a valuable asset for the IAMSLIC membership. Most IAMSLIC members use appropriate discretion and distribute their requests across lenders, but a small number have verged on abuse of the privilege, generating an unduly large percentage of the lending volume. Consequently, the IAMSLIC Resource Sharing Committee closely monitors patterns of use and may need to establish more formal policies.

Initial successes in resource sharing in IAMSLIC came about through group efforts and a philosophical commitment to sharing across geographic, technical and institutional boundaries. But, good intentions need to be put into action. We have benefited from the expertise of one member in particular. Now, other members contribute individually by loading records, offering their collections to borrowers and using the system. Others are exploring how to index OAI-compliant institutional repositories so searches may reveal available additional relevant full-text resources. Library organizations may want to consider a similar approach to resource sharing if the need exists and current tools do not address that need. IAMSLIC is unique in its international personality and subject focus, but we are not unique in our commitment to resource sharing.

\section{References}

Bailey-Hainer, B. K. (2004) Multi-type statewide resource sharing: The Colorado SWIFT experience. Journal of Library Administration ,40 (1/2): 5-22.

Ball, A. (2001) IAMSLIC linking libraries project. In: Tides of Technology, Proceedings of the $26^{\text {th }}$ Annual Conference of the International Association of Aquatic and Marine Science Libraries and Information Centers (ed. by J.W. Markham \& A.L. Duda). IAMSLIC: Fort Pierce, Florida. pp. 63-66.

\begin{tabular}{|l|c|c|}
\hline Library & Fill rate: IAMSLIC (\%) & Fill rate: OCLC (\%) \\
\hline $\begin{array}{l}\text { Hatfield Marine Science Center, } \\
\text { Oregon State University }\end{array}$ & 83 & 67 \\
\hline $\begin{array}{l}\text { Moss Landing Marine Laboratories, } \\
\text { California State Universities }\end{array}$ & 83 & 70 \\
\hline University of Hawaii & 83 & 28 \\
\hline $\begin{array}{l}\text { Oregon Institute Of Marine Biology, } \\
\text { University of Oregon }\end{array}$ & 60 & 70 \\
\hline $\begin{array}{l}\text { Marine Biological Laboratory, Woods Hole, } \\
\text { Massachusetts }\end{array}$ & 71 & 76 \\
\hline Duke Marine Laboratory, Duke University & $20-25$ & 85 \\
\hline
\end{tabular}

Table 2. Sample average fill rates from top lenders with OCLC access. 
Birch, K. and I. Pettman. (2000) Linking distance learners with the UNIverse. In: Libraries Without Walls 3: The Delivery of Library Service to Distant Users (ed. by P. Brophy, S, Fisher and Z. Clarke). Library Association Publishing: London. pp: 166-174.

Brack, V., J. Gilby, P. Stubley and J. Sykes. (1998) Service delivery in a clumped environment: The RIDING Project and the M25 Link Project. The New Review of Information and Library Research, 4: 75-84.

Butler, B. (1997) Resource sharing mechanisms for IAMSLIC. In: Tradition \& Innovation: Planning Our Future, Proceedings of the $22^{\text {nd }}$ Annual Conference of the International Association of Aquatic and Marine Science Libraries and Information Centers (ed. by J.W. Markham \& A.L. Duda). IAMSLIC: Fort Pierce, Florida. pp. 111-116.

Clissman, C., R. Murray, E. Davidson, J. Hands, O. Sijtsma, A. Noordzij, R. Moulton, S. Shanawa, J. Darzentas and I. Pettman. (1998) The UNIverse Project: state-ofthe-art of the standards, softwares and systems which will underpin the development. Part 3: inter library loans protocols; multimedia document delivery; and authentication and directory services. New Library World, 99 (1140): 60-68.

Cornish, G.P. (1991) The impact of networking on international interlibrary loan and document supply. Libri, 41 (4): 272-288.

Duda, A.L., R.L. Meszaros and J.W. Markham. (1997) A month in the life of a mailing list: communication among science and technology librarians. Issues in Science \& Technology Librarianship, 15 (Summer) [Online.] Retrieved December 2005: http://www. library.ucsb.edu/istl/97summer/article1.html

IAMSLIC Z39.50 Distributed Library. [Online.] Accessed December 2005: http://library.csumb.edu/iamslic/ill/ search.php

IAMSLIC. Resource Sharing Committee. (2004) Annual Report 2003/2004. Report submitted to IAMSLIC Executive Board, October 2004.

Leon, E.L, J.L. DeWeese. C.A. Kocjan, B. Peterson-Lugo and B.L. Pytlik Zillig. (2003) Enhanced resource sharing through group interlibrary loan best practices: A conceptual, structural and procedural approach. Portal: Libraries and the Academy, 3 (3): 419-430.

Markham, J. W. (1998) A year in the life of the IAMSLIC Listserver. In: Electronic Information and Publications: Looking to the Electronic Future, Let's Not Forget the Archival Past. Proceedings of the $24^{\text {th }}$ Annual Conference of the International Association of Aquatic and Marine Science Libraries and Information Centers (IAMSLIC) and the $17^{\text {th }}$ Polar Libraries Colloquy (PLC) (ed. by J.W. Markham, A.L. Duda and M. Andrews). IAMSLIC: Fort Pierce, Florida. pp. 339-346.

Markham, J.W. (2004) Listserver monitoring survey report 2003-2004. Report submitted to IAMSLIC Executive Board, October 2004.

Meadows, J., Walker, D. and Barrick, S.O. (1984) MUSSEL: a union list of serials in marine science libraries. Virginia Seagrant Program and the International Association of Marine Science Libraries and Information Centers: Gloucester Pt., VA.

Morris, A. and N. Jacobs. (2000) Experiences of using electronic document delivery services from the workplace and from home. In: Libraries Without Walls 3:
The Delivery of Library Service to Distant Users (ed. by P. Brophy, S, Fisher and Z. Clarke). Library Association Publishing: London. pp. 154-165.

Union List of Marine and Aquatic Serials. [Online.]Accessed August 2005: http://library.csumb.edu/iamslic/ unionlist/

Van Borm, J. (2004) To Russia with love: A European Union project in St. Petersburg for library cooperation in general, ILDS in particular. Interlending \& Document Supply, 32 (3): 159-163.

Watkins, S.G. (2003) The IAMSLIC Z39.50 Distributed Library: facilitating international resource sharing through linked systems and services. In: Bridging the Digital Divide, Proceedings of the $28^{\text {th }}$ Annual Conference of the International Association of Aquatic and Marine Science Libraries and Information Centers (ed. by J.W. Markham and A.L. Duda). IAMSLIC: Fort Pierce, Florida. pp. 33-42.

Watkins, S.G. and Wible, J.G. (1992) Creating a computerbased Union List of aquatic and marine sciences serials. In: Aquatic Information Resources - Tools of Our Trade, Proceedings of the $18^{\text {th }}$ Annual Conference of the International Association of Aquatic and Marine Sciences Libraries and Information Centers (ed. by E. Fuseler and S. Wiest). IAMSLIC: Fort Pierce, Florida. pp. 133-140.

Weech, T.L. (2002) Back to the future - when resource sharing seemed to work. The rise and fall of a successful consortial resource-sharing network. Interlending $\&$ Document Supply, 30(3): 80-86.

Winn, C.P. (1987) International directory of marine science libraries and information centers. Woods Hole Oceanographic Institution and International Association of Marine Science Libraries and Information Centers: Woods Hole, MA.

\section{About the Authors}

Barbara A. Butler is Head Librarian at the Oregon Institute of Marine Biology, a field station branch library of University of Oregon, USA. Her research interests include topics of concern to one-person and remotely located libraries, resource sharing and issue relating to international librarianship. She has been a member of the International Association of Aquatic and Marine Science Libraries and Information Centers (IAMSLIC) since 1991, and is IAMSLIC President-Elect for 2007-2008. She received a BS in Biology and an MS in Range Management from University of California at Davis and her MLIS from University of California at Berkeley. E-mail: butler@uoregon.edu

Janet Webster is Head Librarian at Oregon State University's Hatfield Marine Science Center in Newport, Oregon, USA. Her research interests include collaborative filtering, integration of grey literature into library collections, and global access to local information. She has been a member of IAMSLIC since 1990, serving in various capacities including as President. She was President of the Oregon Library Association in 2001/2002 and 
was honored as Oregon's Librarian of the Year in 2003. She received her undergraduate degree in geography from the University of Chicago, her MLS from Columbia University, and an MS in scientific communication from Oregon State University. E-mail: janet.webster@oregonstate.edu

Steven G. Watkins is Coordinator of Technology Development for the library of California State University, Monterey Bay, USA, where he also serves as the science librarian. His research interests include the customization of open source software applications for interactive user services, the application of federated searching to resource sharing, and the integration of access to harvested institutional repository metadata with Z39.50 query tools. He has been a member of IAMSLIC since 1986, serving in various capacities, including as President and as the primary architect of the IAMSLIC Z39.50
Distributed Library. He received his undergraduate degree in biology from Stanford University and his MLS from the University of California, Berkeley. E-mail: steve_watkins@csumb.edu

Dr James W. Markham has been a science librarian at the University of California, Santa Barbara since 1986, and is interested in subject analysis and improving access to scientific literature. He has been a member of IAMSLIC since 1985 and served as editor of twelve Proceedings of its annual conference, 1993-2004. He served as chair of the IAMSLIC Listserv Monitoring Committee from 2001 to 2004. He received a BA in biology from Stanford University, an MS in marine botany from the University of Washington, a PhD in marine botany from the University of British Columbia, and an MLS from University of Washington. E-mail: markham@library.ucsb.edu 